\title{
Failure to Follow Instructions
}

National Cancer Institute

\section{Source}

National Cancer Institute. Failure to Follow Instructions. NCI Thesaurus. Code C91873.

Problems traced to the user not following the manufacturer's instructions. 